\title{
Practice pattern and use of serum peptide formulation in patients with alopecia: results of an opinion survey among dermatologists in India
}

\author{
Rekha Lanjekar*
}

Department of Dermatology, Yellow ribbon, Dahisar (W), Mumbai, Maharashtra, India

Received: 29 October 2020

Accepted: 05 December 2020

\section{*Correspondence:}

Dr. Rekha Lanjekar,

E-mail: rekha.lanjekar@gmail.com

Copyright: ( $)$ the author(s), publisher and licensee Medip Academy. This is an open-access article distributed under the terms of the Creative Commons Attribution Non-Commercial License, which permits unrestricted non-commercial use, distribution, and reproduction in any medium, provided the original work is properly cited.

\section{ABSTRACT}

To evaluate practice pattern and preference for use of serum peptide formulation by dermatologists for the treatment of alopecia. Dermatologists in India were administered a questionnaire consisting of questions related to number of patients with alopecia seen every week, investigations, prevalence of nutritional deficiencies and use of serum peptide formulation in telogen effluvium (TE) and androgenetic alopecia (AGA). The responses were analysed as number and percentages. Out of 124 dermatologists, $38(31 \%)$ reported that they see 11-15 patients with TE every week and 31 (25\%) reported seeing 11-15 patients of AGA per week. According to 51 (41\%) dermatologists, 40-60\% patients with hair loss have some nutritional deficiency and 95 (77\%) reported that iron deficiency profile, thyroid stimulating hormone (TSH), vitamin B1 and vitamin D level estimation is necessary in patients with TE. A total of $86(69 \%)$ dermatologists preferred serum peptide formulation in patients with TE and AGA. Ninety nine (80\%) and $75(60 \%)$ dermatologists reported "very good" or "good" efficacy of serum peptide in TE and AGA respectively. Ninety nine $(80 \%)$ dermatologists said, gender is not an important criterion for choosing a serum peptide in hair fall. For aesthetics related parameters, Folliserum (Abbott Health care Pvt Ltd) was rated as "Very good" and "Good" by 66 (53\%) and 38 $(31 \%)$ dermatologists respectively. According to dermatologists in India, nutritional deficiency is common in patients with alopecia. Majority of the survey participants rated Folliserum as "Very good" or "Good" for its efficacy and aesthetic parameters.

Keywords: Androgenic alopecia, Serum peptide, Telogen effluvium

\section{INTRODUCTION}

Hair loss is a common problem among people of both genders in India. Hair loss can be distressing to many patients and affect their quality of life. ${ }^{1}$ Patients often visit family physicians for the treatment of hair loss. Some patients may directly visit dermatologist for control of hair loss whereas some are referred to dermatologists by family physicians.

Causes of primary hair loss can be divided into three types; non-scarring alopecia [androgenic alopecia (AGA), female pattern hair loss (FPHL), telogen effluvium (TE), trichotillomania, traction alopecia, tinea capitis, short anagen syndrome] scarring alopecia (e.g. lichen planopilaris, frontal fibrosing alopecia, chronic cutaneous lupus erythematosus, central centrifugal cicatricial alopecia, folliculitis decalvans) and genetic hair disorders. ${ }^{2}$ TE and FPHL are common causes of diffuse alopecia. ${ }^{3}$ AGA is common condition in Asian people and affects both genders. ${ }^{4,5}$ The reported incidence is up to $73 \%$ in general population. ${ }^{4} \mathrm{TE}$ is of relatively sudden onset due to physiologic or emotional stress. ${ }^{1}$ The other causes of TE include childbirth, severe infection, severe chronic illness, thyroid disorders, iron deficiency anemia. ${ }^{6}$

The treatment options for AGA in male include topical minoxidil and oral finasteride whereas in females they 
include topical minoxidil and oral androgens. Other alternative medical therapies have also been suggested.4 A retrospective study reported usefulness of oral minoxidil in hair shedding in chronic TE. ${ }^{7}$ However, topical treatment is preferred over systemic therapy. ${ }^{8}$ Several agents including mineral oil, coconut oil and sunflower oil, have been evaluated for their use in hair fall or prevention of hair damage. ${ }^{9}$ Micronutrients are important components in the normal hair follicle cycle and cellular turnover. ${ }^{10}$ Sulphur amino acids (cysteine and methionine) are useful for keratin hair protein synthesis. ${ }^{11}$ Micronutrients have a role in the management of hair loss especially non-scarring alopecia i.e. AGA, TE and alopecia areata (AA). ${ }^{10}$ Deficiency of micronutrients is a modifiable risk factor in patients with hair loss. ${ }^{12}$ Complementary and alternative medicines have also been tried in the management of alopecia. However, currently there is no robust evidence to suggest its role. A comprehensive review of literature suggests need of more well designed studies to support the role of complementary and alternative medicines. ${ }^{13}$ Considering this, newer treatment options are often sought by both patients and healthcare professionals involved in the treatment of alopecia.

Folliserum is a hair growth serum consisting of multiple nutritional ingredients targeted for hair growth. It is applied topically with an objective of improving quality of hair, increase growth of new hair and providing strength to the hair roots. Currently there are no studies examining usage pattern and preference of serum based formulations in the treatment of hair loss in Indian patients.

\section{Objectives}

The objective of this survey was to study practice pattern and preference for use of serum peptide formulation by dermatologists for the treatment of alopecia.

\section{METHODS}

In this questionnaire-based survey, dermatologists from eight major cities (Mumbai, Delhi, Chennai, Bangalore, Pune, Kolkata, Hyderabad and Nagpur) were contacted from July 2017 to October 2017 for their willingness to participate.

A questionnaire was administered personally by the trained person to dermatologists willing to participate in the survey. The questions covered number of patients with alopecia seen every week, necessary investigations in these patients, percentage of patients with alopecia having nutritional deficiencies and preference for serum peptide formulation.

In respondents using serum peptide formulation, frequency and duration of administration, adherence, response to treatment, co-prescriptions and overall response were also recorded. All the questions were close ended. Responses were collected separately for TE and AGA and analysed in the form of number and percentages.

\section{RESULTS}

A total of 124 dermatologists from India participated in this survey. A total of $38(31 \%)$ reported that they see $11-$ 15 patients with TE every week whereas 29 (23\%) respondents reported seeing more than 20 patients per week. Thirty one (25\%) dermatologists reported that they see 5-10 patients with TE per week (Table 1). A total of 31 (25\%) dermatologists reported seeing 11-15 patients of AGA per week whereas $29(23 \%)$ dermatologists reported that they see 5-10 and 16-20 patients each of AGA per week (Table 1).

\section{Table 1: Number of patients visiting dermatologists per week.}

\begin{tabular}{|ll|}
\hline Parameter & N $(\%)$ of doctors \\
\hline TE & \\
\hline $\mathbf{5 - 1 0}$ & $31(25)$ \\
\hline $\mathbf{1 6 - 2 0}$ & $38(31)$ \\
\hline$>\mathbf{2 0}$ & 0 \\
\hline No response & $29(23)$ \\
\hline AGA & $26(21)$ \\
\hline $\mathbf{5 - 1 0}$ & \\
\hline $\mathbf{1 1 - 1 5}$ & $29(23)$ \\
\hline $\mathbf{1 6 - 2 0}$ & $31(25)$ \\
\hline $\mathbf{2 0}$ & $29(23)$ \\
\hline No response & 0 \\
\hline
\end{tabular}

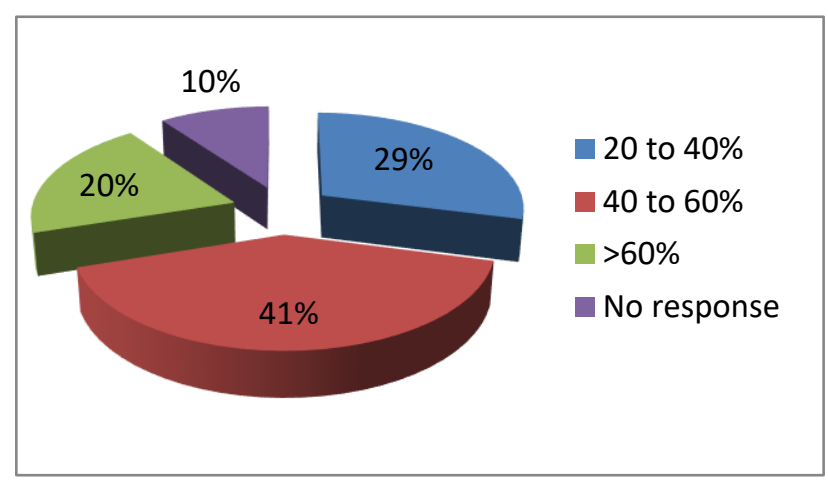

Figure 1: Percentage of dermatologists responding prevalence of underlying nutritional deficiency in patients with hair loss.

According to $51(41 \%)$ dermatologists, $40-60 \%$ patients with hair loss have some nutritional deficiency whereas 36 (29\%) dermatologists said 20-40\% patients with alopecia have some nutritional deficiency. A total of $24(20 \%)$ dermatologists reported that over $60 \%$ patients have nutritional deficiency.

A total of $95(77 \%)$ dermatologists mentioned that iron deficiency profile, thyroid stimulating hormone (TSH), vitamin $\mathrm{B} 1$ and vitamin D level estimation is necessary in patients with TE. A total of $16(13 \%)$ dermatologists felt iron deficiency profile and TSH estimation is necessary in 
patients with TE. Five (4\%) dermatologists mentioned necessity of only TSH level estimation in patients with TE whereas $7(6 \%)$ dermatologists did not respond to this question.

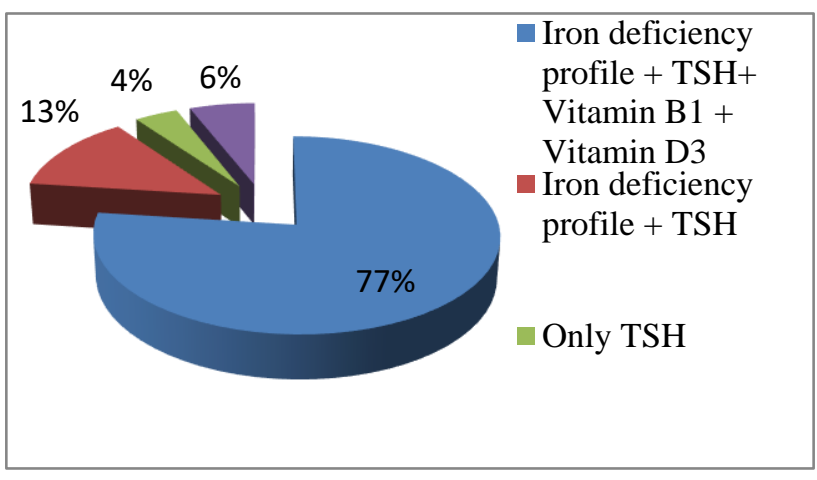

Figure 2: Opinion of dermatologists regarding need of investigations in patients with telogen effluvium.

A total of $95(77 \%)$ dermatologists mentioned that iron deficiency profile, thyroid stimulating hormone (TSH), vitamin B1 and vitamin D level estimation is necessary in patients with TE. A total of $16(13 \%)$ dermatologists felt iron deficiency profile and TSH estimation is necessary in patients with TE. Five (4\%) dermatologists mentioned necessity of only TSH level estimation in patients with TE whereas $7(6 \%)$ dermatologists did not respond to this question.

A total of $86(69 \%)$ dermatologists preferred use of serum peptide formulation in patients with TE as well as AGA. Twice daily usage of serum peptide formulation in TE and AGA was reported by 58 (47\%) and 33 (27\%) dermatologists respectively. Ninety nine $(80 \%)$ and 75 $(60 \%)$ dermatologists reported "Very good" or "Good" efficacy of serum peptide formulation in TE and AGA respectively (Table 2 ).

In patients with TE, $60(48 \%)$ and $38(31 \%)$ dermatologists reported use of serum peptide formulation for 3 months and 6 months respectively. In AGA, 36 (29\%) and 35 (28\%) dermatologists reported using peptide formulation for 6 months and more than 6 months respectively. According to $55(44 \%)$ and $47(38 \%)$ dermatologists desired control is achieved in $41-60 \%$ and $61-80 \%$ patients with TE respectively. In AGA, 30 (27\%) and 52 (42\%) dermatologists reported achievement of desired control in $21-40 \%$ and $41-60 \%$ patients respectively. A total of 102 (82\%) and $88(71 \%)$ dermatologists reported "Very good" or "Good" adherence with serum peptide formulation in patients with TE and AGA respectively (Table 2).

Twenty five (20\%) and 27 (30\%) dermatologists reported using Folliserum monotherapy in $21-40 \%$ and $41-60 \%$ patients with TE respectively whereas 40 (32\%) and 32 (26\%) dermatologists reported use of monotherapy in 0 $20 \%$ and $21-40 \%$ patients respectively. A total of 46 (27\%) dermatologists reported using minoxidil along with
Folliserum in patients with TE whereas $16(13 \%)$ reported using multivitamin/nutritional supplement as co-therapy. A total $66(53 \%)$ dermatologists reported using minoxidil based combination as co-therapy in patients with AGA. In patients with TE and AGA, overall "Very good" or "Good" experience was reported by $100(81 \%)$ and 88 (71\%) dermatologists respectively (Table 2 ).

Table 2: Opinion of dermatologists regarding use of serum peptide formulation in hair fall.

\begin{tabular}{|c|c|c|}
\hline Parameter & $\begin{array}{l}\text { TE } \\
\mathbf{N}(\%)\end{array}$ & $\begin{array}{l}\text { AGA } \\
\mathbf{N}(\%)\end{array}$ \\
\hline $\begin{array}{l}\text { Preference for serum } \\
\text { peptide formulation }\end{array}$ & $\begin{array}{l}\text { TE+AGA: } \\
86 \text { (69), only } \\
\text { TE: } 31 \text { (25) }\end{array}$ & $\begin{array}{l}\text { TE+AGA: } \\
86(69)\end{array}$ \\
\hline Twice a day dosage & $58(47)$ & $33(27)$ \\
\hline \multicolumn{3}{|l|}{ Efficacy } \\
\hline Very good & $61(49)$ & $25(20)$ \\
\hline Good & $38(31)$ & $50(40)$ \\
\hline \multicolumn{3}{|l|}{$\begin{array}{l}\text { Duration of use } \\
\text { (months) }\end{array}$} \\
\hline 3 & $60(48)$ & NA \\
\hline 6 & $38(31)$ & $36(29)$ \\
\hline$>6$ & NA & $35(28)$ \\
\hline \multicolumn{3}{|l|}{$\begin{array}{l}\text { Achievement of desired } \\
\text { control }(\%)\end{array}$} \\
\hline $21-40$ & NA & $30(27)$ \\
\hline $41-60$ & $55(44)$ & $52(42)$ \\
\hline $61-80$ & $47(38)$ & NA \\
\hline \multicolumn{3}{|l|}{ Adherence } \\
\hline Very good & $60(48)$ & $38(31)$ \\
\hline Good & $42(34)$ & $50(40)$ \\
\hline \multicolumn{3}{|l|}{$\begin{array}{l}\text { Use as monotherapy } \\
(\%)\end{array}$} \\
\hline $0-20$ & NA & $40(32)$ \\
\hline $21-40$ & $25(20)$ & $32(26)$ \\
\hline $41-60$ & $27(30)$ & NA \\
\hline \multicolumn{3}{|l|}{ Co-prescription } \\
\hline Minoxidil & $46(37)$ & NA \\
\hline $\begin{array}{l}\text { Minoxidil based } \\
\text { combination }\end{array}$ & NA & $66(53)$ \\
\hline $\begin{array}{l}\text { Multivitamin/nutritional } \\
\text { Supplement }\end{array}$ & $16(13)$ & NA \\
\hline \multicolumn{3}{|l|}{ Overall experience } \\
\hline Very good & $63(51)$ & $38(31)$ \\
\hline Good & $37(30)$ & $50(40)$ \\
\hline
\end{tabular}

According to $99(80 \%)$ dermatologists, gender is not an important criterion for choosing a serum peptide formulation in hair fall. Patients with any type of hair loss can use serum peptide formulation. A total of 45 (36\%) dermatologists preferred to keep 2 hours between application of monoxidil and Folliserum whereas 30 (27\%) prefer to keep 1 hour. In terms of aesthetic parameters (non-sticky and non-greasy), Folliserum was rated as "Very good" and "Good" by 66 (53\%) and 38 $(31 \%)$ dermatologists respectively. 


\section{DISCUSSION}

In the questionnaire based opinion survey we examined management pattern of alopecia (TE and AGA) with focus on serum based formulations.

Several investigations are ordered in patients with hair loss to identify the cause. Among them are complete blood count, routine urine examination, serum ferritin and thyroid function tests. ${ }^{3}$ Over three forth of the participants in our survey reported that iron deficiency, TSH, vitamin B1 and vitamin D3 are necessary investigations in patients with TE. This is relevant because iron deficiency and thyroid disorders are reported to be the common conditions associated with diffuse hair loss. ${ }^{3}$ Diffuse alopecia is also common in patients with autoimmune hyperthyroidism patients. $^{14}$

Vitamins including vitamin $\mathrm{C}$, vitamin $\mathrm{A}$ and $\mathrm{B}$-complex vitamins also have a role on the state of hairs. Vitamin D has been suggested to have a role in differentiation of hair follicle. ${ }^{11}$ In our survey, many dermatologists felt B1 and vitamin $\mathrm{D}$ level estimation is necessary in patients with TE.

According to over two third survey participants, serum peptides have a role in the management of TE and AGA irrespective of gender. Affinity for hair proteins and structure and molecular weight of the components decides its ability to penetrate inside the hair shaft and prevent loss of proteins from hairs. ${ }^{9}$ In this survey, desired control was rated positively by more than $82 \%$ in TE (41-80\% desired control) and 69\% dermatologists in AGA (21-60\% desired control). This is another surrogate marker for the efficacy of Folliserum.

Aesthetic properties are important in acceptance of the formulation. For example, mineral oil is commonly used in hair oil formulations due to its non-greasy property. ${ }^{9}$ Folliserum is non-sticky and non-greasy formulation. Most (84\%) dermatologists in this survey rated Folliserum as "Very good" or "Good" for its aesthetic properties. This suggests no significant concerns among dermatologists for its acceptability by the patients. Treatment for AGA can be broadly divided into androgen independent medicines (e.g. minoxidil) and androgen dependent medicines (e.g. finasteride, cyproterone acetate, spironolactone). ${ }^{15}$ Topical minoxidil $2 \%$ with or without antiandrogens and finestride are the other pharmacological options for management of FPHL. ${ }^{3}$ A cross sectional study among participants with hair loss reported amino acid and micronutrient deficiencies in all types of hair loss. ${ }^{16}$ These data indicates importance of minoxidil and nutritional supplements in people with hair loss. Some dermatologists in our survey reported using minoxidil and multivitamin/nutritional supplement along with Folliserum in patients with TE.

In AGA 53\% dermatologists from our survey reported using minoxidil based combination along with Folliserum. This practice can be supported by results of a randomized trial showing no significant improvement with mesotherapy in male AGA over topical 5\% minoxidil. ${ }^{17}$

An initial response in FPHL (AGA) may take about 12 or 24 months and needs long term treatment to maintain the effect. ${ }^{15}$ In our survey too dermatologists reported use of long term therapy in patients with AGA as compared to those with TE. According to dermatologists in our survey, treatment in TE range between 3-6 months in TE whereas in AGA, it is 6 months or more. Overall experience in TE and AGA was rated as "Very good" or "Good" by 100 $(81 \%)$ and $88 \quad(71 \%)$ dermatologists respectively, indirectly suggesting satisfaction for its efficacy, tolerability, adherence and aesthetic related parameters. $\mathrm{TE}$ is more common in female especially during postpartum period. Moreover, they commonly consult medical practitioners because they find it more troublesome than men do. ${ }^{18}$

It is important to note, according to $80 \%$ dermatologists participated in the survey, gender is not an important criterion for choosing a serum peptide formulation in the management of hair fall. Overall findings of survey suggest well acceptance of serum peptide in the management of hair loss in both genders and both conditions i.e. TE as well as AGA.

Our study has some limitations. First, although efforts were made to collect responses from dermatologists across India, the selection of participants was done by convenience method of sampling. Secondly, the number of respondents was small. Region wise analysis of the responses was also not performed. Considering these limitations, care should be taken while extrapolating the results of this survey.

\section{CONCLUSION}

According to dermatologists in India, nutritional deficiency is common in patients with alopecia. Majority of the survey participants rated Folliserum as "Very good" or "Good" for its efficacy (both in TE and AGA) and aesthetic parameters.

\section{ACKNOWLEDGEMENTS}

The author would like to thank Dr. Anant Patil for assisting in the development of this manuscript.

Funding: The study was funded by Abbott Healthcare Pvt. Ltd Conflict of interest: None declared Ethical approval: Not required

\section{REFERENCES}

1. Phillips TG, Slomiany WP, Allison R. Hair loss: Common causes and treatment. Am Fam Physician. 2017;96:371-8. 
2. Pratt $\mathrm{CH}$, King LE, Messenger AG, Christiano AM, Sundberg JP. Alopecia areata. Nat Rev Dis Primers. 2017;3:17011.

3. Shrivastava SB. Diffuse hair loss in an adult female: approach to diagnosis and management. Indian $\mathrm{J}$ Dermatol Venereol Leprol. 2009;75:20-7.

4. Lee WS, Lee HJ. Characteristics of androgenetic alopecia in Asian. Ann Dermatol. 2012;24:243-52.

5. Salman KE, Kucukunal NA, Altunay IK, Cerman AA. Frequency, severity and related factors of androgenetic alopecia in dermatology outpatient clinic: hospital-based cross-sectional study in Turkey. An Bras Dermatol. 2017;92:35-40.

6. Shapiro J, Wiseman M, Lui H. Practical management of hair loss. Can Fam Physician. 2000;46:1469-77.

7. Perera E, Sinclair R. Treatment of chronic telogen effluvium with oral minoxidil: A retrospective study. F1000Research. 2017;6:1650.

8. Santos Z, Avcil P, Hamblin MR. Drug discovery for alopecia: gone today, hair tomorrow. Expert Opin Drug Discov. 2015;10:269-92.

9. Rele AS, Mohile RB. Effect of mineral oil, sunflower oil, and coconut oil on prevention of hair damage. $\mathrm{J}$ Cosmet Sci. 2003;54:175-92.

10. Almohanna HM, Ahmed AA, Tsatalis JP, Tosti A. The role of vitamins and minerals in hair loss: A review. Dermatol Ther (Heidelb). 2019;9:51-70.

11. Goluch-Koniuszy ZS. Nutrition of women with hair loss problem during the period of menopause. Menopause Rev. 2016;15:56-61.
12. Thompson JM, Mirza MA, Park MK, Qureshi AA, Cho E. The role of micronutrients in alopecia areata: A Review. Am J Clin Dermatol. 2017;18:663-79.

13. Hosking A-M, Juhasz M, Mesinkovska NA. Complementary and alternative treatments for alopecia: A comprehensive review. Skin Appendage Disord. 2019;5:72-89.

14. Artantas S, Gul U, Kilic A, Guler S. Skin findings in thyroid diseases. Eur J Intern Med. 2009;20:158-61.

15. Dinh QQ, Sinclair R. Female pattern hair loss: Current treatment concepts. Clin Interven Aging. 2007:2:189-99.

16. Gowda D, Premalatha V, Imtiyaz DB. Prevalence of nutritional deficiencies in hair loss among indian participants: Results of a cross-sectional study. Int J Trichol. 2017;9:101-4.

17. Gajjar PC, Mehta HH, Barvaliya M, Sonagra B. Comparative study between mesotherapy and topical $5 \%$ minoxidil by dermoscopic evaluation for androgenic alopecia in male: a randomized controlled trial. Int J Trichol. 2019;11:58-67.

18. Grover C, Khurana A. Telogen effl uvium. Indian J Dermatol Venereol Leprol. 2013;79:591-603.

Cite this article as: Lanjekar R. Practice pattern and use of serum peptide formulation in patients with alopecia: results of an opinion survey among dermatologists in India. Int $\mathbf{J}$ Res Dermatol $2021 ; 7: 150-4$. 